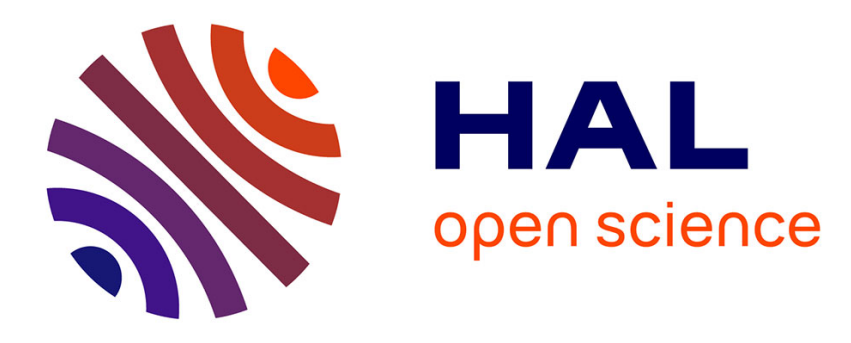

\title{
Use of stylet and airway management procedure in critically ill patients. Author's reply
}

\author{
Samir Jaber, Audrey de Jong
}

\section{To cite this version:}

Samir Jaber, Audrey de Jong. Use of stylet and airway management procedure in critically ill patients. Author's reply. Intensive Care Medicine, In press, 10.1007/s00134-021-06518-8 . hal-03346525

\section{HAL Id: hal-03346525 \\ https://hal.science/hal-03346525}

Submitted on 16 Sep 2021

HAL is a multi-disciplinary open access archive for the deposit and dissemination of scientific research documents, whether they are published or not. The documents may come from teaching and research institutions in France or abroad, or from public or private research centers.
L'archive ouverte pluridisciplinaire HAL, est destinée au dépôt et à la diffusion de documents scientifiques de niveau recherche, publiés ou non, émanant des établissements d'enseignement et de recherche français ou étrangers, des laboratoires publics ou privés. 


\section{Use of stylet and airway management procedure in critically ill patients. Author's reply}

Samir Jaber ${ }^{1,2^{*}}$ and Audrey De Jong ${ }^{1}$

We thank Masuda et al. for their letter [1] concerning our article, entitled "Effect of the use of an endotracheal tube and stylet versus an endotracheal tube alone on first-attempt intubation success: a multicentre, randomized clinical trial in 999 patients" [2]. We value that the authors of the letter appreciated the clinical value of the study and its impact on intubation providers in daily clinical practice.

As accurately stated by Masuda et al., it is important to emphasize that the operators of the STYLETO pragmatic study were prompted to follow the "Montpellier-Intubation-Protocol" [3] (Table 1). This probably accounts for the lower rate of severe complications reported in the "STYLETO" study [2] in comparison with the international "INTUBE" study [4]. Briefly, the "Montpellier-Intubation-Protocol" [3] aims to prevent severe hypoxemia and severe collapse, in three time-periods: (1) before intubation (fluid-loading, early introduction of vasopressors, preoxygenation with noninvasive ventilation (NIV) without or with high-flow nasal cannula oxygen (HFNO) called OPTINIV method for apnoeic oxygenation, preparation of sedation and presence of two operators), (2) during intubation (rapid-sequence induction using shortacting hypnotics and a rapid-onset muscle relaxant) and (3) after intubation (capnography to check correct tube position in the trachea, long-term sedation, protective ventilation with low airway pressure at first and a recruitment manoeuvre following intubation after hemodynamic stabilization).
We totally agree with the authors of the letter that the drugs used in the STYLETO study [2], mostly ketamine and etomidate may have an impact on the lower complication rate observed in the STYLETO study in comparison with the INTUBE study [4], where propofol was widely used. Moreover, the OPTINIV method associating use of NIV for preoxygenation (the reference method in severe hypoxemic patients) and HFNO for both preoxygenation and apnoeic oxygenation, suggested a superiority of NIV associated to HFNO, compared to NIV plus sham HFNO. Both methods of preoxygenation (NIV alone and OPTINIV) were little-used in the INTUBE study [4], whereas used in over half of the cases in the STYLETO study [2]. Another very important point is the use of capnography, used in only $34.5 \%$ of all patients in the INTUBE study. In comparison, capnography was used in more than $84 \%$ of patients in the STYLETO study. The use of capnography is of prime importance for a quick check of the tracheal position of the tracheal tube, to enable earlier recognition of an oesophageal intubation and reduce associated complications.

It is worth noting that a simplified version of the Montpellier-intubation-protocol [5] was externally validated by an American team and associated with an improvement in first-pass intubation success rates and a reduction in the rate of intubation-related complications. As nicely written by Masuda et al. [1], using the Montpellierintubation-protocol [3] first described by Jaber et al. in 2010 (Table 1) may help to decrease intubation-related complications.

\footnotetext{
*Correspondence: s-jaber@chu-montpellier.fr

${ }^{1}$ Department of Anesthesia and Intensive Care Unit, Regional University Hospital of Montpellier, St-Eloi Hospital, University of Montpellier, 


\section{Pre-intubation}

1. Two operators (i.e., 4 hands)

2. Fluid loading if no cardiogenic pulmonary oedema

3. Systematic early introduction of vasopressors

4. Preparation of long-term sedation

5. For preoxygenation, upright position (20-30 bed) when possible

6. Preoxygenation during at least 3 min with noninvasive ventilation in case of hypoxemic acute respiratory failure $\left(\mathrm{FiO}_{2} 100 \%\right.$, pressure support between 5 and $10 \mathrm{cmH}_{2} \mathrm{O}$ to obtain an expired tidal volume between 6 and $8 \mathrm{~mL} / \mathrm{kg}$ and a PEEP of $5 \mathrm{cmH}_{2} \mathrm{O}$ ), associated with apnoeic oxygenation when available and high-risk of hypoxaemia (OPTINIV method)

\section{Per-intubation}

7. Use first video laryngoscope for intubation procedure, if no video laryngoscope available, consider direct Macintosh laryngoscopy with Stylet

8. Rapid sequence induction:

Etomidate $0.2-0.3 \mathrm{mg} / \mathrm{kg}$ or ketamine $1.5-3 \mathrm{mg} / \mathrm{kg}$ or propofol $1.5-3 \mathrm{mg} / \mathrm{Kg}$ intravenous

Succinylcholine $1 \mathrm{mg} / \mathrm{kg}$ intravenous (without contra-indications)

Rocuronium: $1.2 \mathrm{mg} / \mathrm{kg}$ intravenous in case of contra-indications to succinylcholine

9. Sellick manoeuvre

10. Ventilation in case of oxygenation desaturation $<90 \%$ or if elevated risk of oxygen desaturation higher than the risk of aspiration

\section{Post-intubation}

11. Capnography to check correct placement in trachea of the tube

12. Increase vasopressors especially if diastolic arterial pressure $<35 \mathrm{mmHg}$ or systolic arterial pressure $<90 \mathrm{mmHg}$

13. Start early long-term sedation

14. Low airway pressure ventilation at the beginning: tidal volume $6-8 \mathrm{~mL} / \mathrm{kg}, \mathrm{PEEP}<5 \mathrm{cmH}_{2} \mathrm{O}$ and respiratory rate between 10 and $20 / \mathrm{min}, \mathrm{FiO} 2,100 \%$ for a plateau pressure $<30 \mathrm{cmH}_{2} \mathrm{O}$ (protective ventilation will be started after hemodynamic stabilization)

15. Recruitment manoeuvre: PEEP of $30-40 \mathrm{~cm} \mathrm{H}_{2} \mathrm{O}$ during $20-30 \mathrm{~s}, \mathrm{FiO}_{2} 100 \%$ (if no cardiovascular collapse and in non-hypovolemic patient) 16. Cuff pressure of the tube between 25 and $30 \mathrm{cmH}_{2} \mathrm{O}$ without leaks

The recommendations are not mandatory, but they have to be "considered", according to some randomized controlled trials, some observational studies and expert opinions [3]

$\mathrm{FiO}_{2}$ Inspired Oxygen Fraction, PEEP positive end-expiratory pressure, OPTINIV noninvasive ventilation with high-flow nasal cannula oxygen

\section{Author details}

${ }^{1}$ Department of Anesthesia and Intensive Care Unit, Regional University Hospital of Montpellier, St-Eloi Hospital, University of Montpellier, PhyMedExp, INSERM U1046, CNRS UMR, 9214 Montpellier Cedex 5, France. ${ }^{2}$ Département d'Anesthésie Réanimation B (DAR B), 80 Avenue Augustin Fliche, 34295 Montpellier, France.

\section{Declarations}

\section{Conflicts of interest}

SJ reports receiving consulting fees from Drager, Medtronic, Baxter, FreseniusXenios, and Fisher \& Paykel. ADJ reports receiving consulting fees from Medtronic.

\section{Ethics committee approval}

Not applicable.
2. Jaber S, Rollé A, Godet T, Terzi N, Riu B, Asfar P, Bourenne J, Ramin S, Lemiale V, Quenot JP, Guitton C, Prudhomme E, Quemeneur C, Blondonnet R, Biais M, Muller L, Ouattara A, Ferrandiere M, Saint-Léger P, Rimmelé T, Pottecher J, Chanques G, Belafia F, Chauveton C, Huguet H, Asehnoune K, Futier E, Azoulay E, Molinari N, De Jong A (2021) Effect of the use of an endotracheal tube and stylet versus an endotracheal tube alone on firstattempt intubation success: a multicentre, randomised clinical trial in 999 patients. Intensive Care Med 47:653-664

3. Jaber S, Jung B, Corne P, Sebbane M, Muller L, Chanques G, Verzilli D, Jonquet O, Eledjam JJ, Lefrant JY (2010) An intervention to decrease complications related to endotracheal intubation in the intensive care unit: a prospective, multiple-center study. Intensive Care Med 36:248-255

4. Russotto V, Myatra SN, Laffey JG, Tassistro E, Antolini L, Bauer P, Lascarrou JB, Szuldrzynski K, Camporota L, Pelosi P, Sorbello M, Higgs A, Greif R, Putensen C, Agvald-Öhman C, Chalkias A, Bokums K, Brewster D, Rossi E, Fumagalli R, Pesenti A, Foti G, Bellani G (2021) Intubation practices and adverse peri-intubation events in critically ill patients from 29 countries. JAMA 325:1164-1172

5. Corl KA, Dado C, Agarwal A, Azab N, Amass T, Marks SJ, Levy MM, Merchant RC, Aliotta J (2018) A modified Montpellier protocol for intubating intensive care unit patients is associated with an increase in first-pass intubation success and fewer complications. J Crit Care 44:191-195

\section{References}

1. Masuda T, Nosaka N, Uchimido R, Nagashima M (2021) Use of stylet and airway management procedure in critically ill patients. Intensive Care Med. https://doi.org/10.1007/s00134-021-06476-1 